\title{
Friction torque in grease lubricated thrust ball bearings
}

\author{
Tiago Cousseau, Beatriz Graça, Armando Campos, Jorge Seabra
}

\section{A B S T R A C T}

Thrust ball bearings lubricated with several different greases were tested on a modified Four-Ball Machine, where the Four-Ball arrangement was replaced by a bearing assembly. The friction torque and operating temperatures in a thrust ball bearing were measured during the tests. At the end of each test a grease sample was analyzed through ferrographic techniques in order to quantify and evaluate bearing wear.

A rolling bearing friction torque model was used and the coefficient of friction in full film lubrication was determined for each grease, depending on the operating conditions.

The experimental results obtained showed that grease formulation had a very significant influence on friction torque and operating temperature. The friction torque depends on the viscosity of the grease base oil, on its nature (mineral, ester, PAO, etc.), on the coefficient of friction in full film conditions, but also on the interaction between grease thickener and base oil, which affected contact replenishment and contact starvation, and thus influenced the friction torque.

Keywords:

Rolling bearings

Friction torque

Power loss

Biodegradable greases

\section{Introduction}

One third of all energy used in industrial countries goes to overcome friction. High friction often results in high wear and more than $30 \%$ of the production in industry goes to replace worn out products. Therefore, controlling and reducing friction and wear is one major challenge in the attempt to reach a sustainable society with low energy consumption and reduced environmental climate change effects [1].

For that reason the minimization of the power loss and the use of the biodegradable greases have been attracting considerable attention [2,3]. However, the performance of biodegradable greases is not yet well known, mainly in terms of rolling bearing wear and power loss. Consequently, several authors have been studying the influence of grease formulation on the coefficient of friction [4-6], and new experimental methods and analytical tools have been developed, aiming to compare the tribological and energetic behaviour of these new biodegradable greases with the reference ones [7].

In this work a Four-Ball machine was modified for testing thrust ball bearings, allowing to compare the performance of different lubricating greases, and a numerical model was used to predict the internal energy loss. Correlation factors will be considered in order to determine the coefficient of friction for the lubricating greases.

\section{Methods and materials}

\subsection{Experimental method}

Torque tests were performed using a modified Four-Ball machine, where the Four-Ball arrangement was replaced by a rolling bearing assembly, as shown in Fig. 1. For the actual analysis a 51107 thrust ball bearing was used [7].

The rolling bearing assembly is divided in two parts: the shaft adapter (6), directly connected to the machine shaft and supporting the bearing upper race (5); a lower race support (2) and the bearing lower race (5), both clamped to the bearing housing (1). In operation, the internal bearing torque is transmitted to the torque cell (11) through the bearing housing (1). This assembly has five thermocouples (I-V), measuring temperatures at strategic locations (see Fig. 1) which are used to monitor the temperature inside the bearing assembly (IV), near to the rolling bearing and grease (III) and to evaluate the heat evacuation from the bearing housing into the surrounding environment (I, II and $\mathrm{V}$ ). The rolling bearing assembly is submitted to a continuous air convection forced by two fans, having $38 \mathrm{~mm}$ in diameter and 


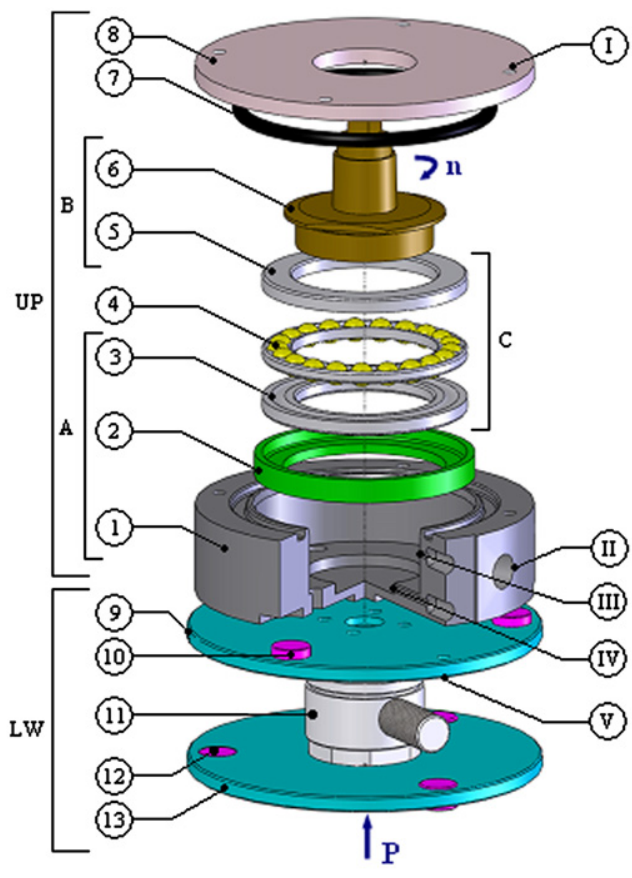

1 - Bearing house

2 - Lower race support

3 - Bearing lower race

4 - Rolling element and cage assembly

5 - Bearing upper race

6 - Shaft adapter

7 - Retainer

8 - Cover

9 - Upper protecting plate

10 - Upper conection pins

11 - Torque cell

12 - Lower connection pins

13 - Lower protecting plate

I - Cover temperature

II - Bearing hause temperature

III - Grease temperature

IV - Internal temperature

$\mathrm{V}$ - Inferior temperature

P - Load

n - Rotational speed

Fig. 1. Schematic view of the rolling bearing assembly with torque cell.

running at $2000 \mathrm{rpm}$, keeping the air temperature surrounding the bearing house almost constant during the test.

The test procedure is conditioned by several factors, including the limitation of the Four-ball Machine operating conditions and the characteristics of the torque transducer [8]. Thus, the torque measurements were performed in three periods of 2 min each, under a constant axial load of $7000 \mathrm{~N}$, rotational speeds between 500 and $2000 \mathrm{rpm}$ and stabilized operating temperatures.

Wear tests were also carried-out under an axial load of $7000 \mathrm{~N}$, submitted to continuous air-forced convection but with a constant rotational speed of $1000 \mathrm{rpm}$ and during $48 \mathrm{~h}$. In these tests just the operating temperatures were measured.

A detailed presentation of this experimental procedure may be found in [8].

\subsection{Grease characterization}

Six different lubricant greases were tested: MG1 and MG2 greases, formulated with mineral base oil and lithium thickener; EG1 and EG2 formulated with ester base oil and both thickened with lithium and calcium, but EG2 also had polyurea; PG1 and PG2 greases, thickened with polypropylene and formulated with polyalphaolefins base oil (PG1) and a mix of a diester with a vegetal base oil (PG2). The polymeric greases are made with a new technology based on non-polar thickener. The physical characteristics of all products are presented in Table 1.

Three of these greases (EG1, EG2 and PG2) passed the tests for biodegradability (OECD 301F and SS155470 class B) and ecotoxicity (OECD 202). The base oil viscosities were measured using an Engler viscometer; the viscosity parameters were calculated through base oil viscosity. Additional properties were provided by the grease manufacturers.

The lubricant parameter $(L P=\eta \alpha)$ shown in Table 1 , is defined by the product of the lubricant dynamic viscosity $(\eta)$ by the pressure-viscosity coefficient $(\alpha)$ at atmospheric pressure [9], and can be directly related to the lubricant film thickness in an EHD contact [10] by the following equation:

$h_{0} \propto(\eta \alpha)^{0.707}$

The grease rheological parameters were measured using a cone-plate geometry CP50-2 $\left(2.02^{\circ} ; 4.997 \mathrm{~mm}\right)$, in sweep and flow tests at ambient temperature $\left(20^{\circ} \mathrm{C}\right)$ on a Physica MCR 301 rheometer. The grease rheological parameters are shown in Table 2.

Scanning electron microscopy was performed on a JEOL JSM 35C/Noran Voyager to better characterize the greases (see Fig. 2). The thickener structure images show large differences among the lubricating greases, which are related to the thickener/base oil interaction and the manufacturing process. MG1 and MG2 are a structured systems based on entanglement networks, which present long and large lithium fibres, but MG2 shows shorter and thicker fibres than MG1. EG1 and EG2 greases contain some large calcium particles and the lithium fibres are shorter and thinner than MG1 and MG2. PG1 and PG2 greases seem to have a more homogeneous thickener structure, although, it is easily damaged by the energy of the incident electron beam used in high magnification $(20,000 \times)$.

\section{Friction torque model for thrust ball bearings}

The rolling bearing friction torque model developed by SKF [11], presented in Appendix A, can be used to predict the friction torque in the thrust ball bearings tested, using the operating temperature measured during these tests, and the predict values can be compared with the friction torque measurements.

The $R_{1}$ and $S_{1}$ constants (see Appendix A, Eqs. (A.3) and (A.7)) are internal geometric constants of the bearing, taking into account the size of the bearing, the number and size of rolling elements, contact osculations, etc. Thus, the values of the $R_{1}$ and $S_{1}$ constants depend on bearing type and bearing series [7].

The thrust ball bearings are among the very few types of bearings for which "universal" constants are provided, regardless 
Table 1

Physical characteristics of the lubricant greases.

\begin{tabular}{|c|c|c|c|c|c|c|}
\hline Designation & MG1 FUCHS & MG2 KLUBER ${ }^{\mathrm{a}}$ & EG1 ROWE & EG2 ROWE & PG1 $A X E L^{\mathrm{a}}$ & PG2 AXEL $L^{\mathrm{a}}$ \\
\hline Biodegradability (\%) b & - & - & $>60$ & 60 & - & $>60$ \\
\hline Toxicity (\%) b & - & - & $>45$ & $>45$ & - & $>45$ \\
\hline Base oil ${ }^{b}$ & Mineral & Mineral & Ester & Ester & PAO & Ester+vegetal \\
\hline Thickener ${ }^{\mathrm{b}}$ & $\mathrm{Li}$ & $\mathrm{Li}$ & $\mathrm{Li} / \mathrm{Ca}$ & Li/Ca-Polyurea & Polypropylene & Polypro-pylene \\
\hline \multicolumn{7}{|l|}{ Base oil properties } \\
\hline Base oil viscosity at $40{ }^{\circ} \mathrm{C}\left(\mathrm{mm}^{2} / \mathrm{s}\right)$ & 230 & 180 & 91.8 & 91.8 & 47 & 32.5 \\
\hline Base oil viscosity at $100{ }^{\circ} \mathrm{C}\left(\mathrm{mm}^{2} / \mathrm{s}\right)$ & 17.5 & 14 & 14.5 & 14.5 & 8 & 6.7 \\
\hline Specific gravity $\left(\mathrm{g} / \mathrm{cm}^{3}\right)$ & 0.90 & 0.90 & 0.95 & 0.95 & 0.83 & 0.91 \\
\hline Piezoviscosity at $40{ }^{\circ} \mathrm{C}\left(10^{-9} \mathrm{~Pa}^{-1}\right)$ & 21.09 & 20.38 & 12.21 & 12.21 & 12.32 & 10.60 \\
\hline$\left(\alpha_{0.2 \mathrm{GPa}}=s v^{t}\right) s$ & 9.90 & 9.90 & 6.61 & 6.61 & 7.38 & 6.61 \\
\hline$t$ & 0.14 & 0.14 & 0.14 & 0.14 & 0.13 & 0.14 \\
\hline$L P$ at $40^{\circ} \mathrm{C} \times 10^{-9}$ (lubricant parameter) & 4.39 & 3.29 & 1.07 & 1.07 & 0.50 & 0.31 \\
\hline \multicolumn{7}{|l|}{ Grease properties } \\
\hline NLGI no. (DIN 518181) b & 2 & 2 & 2 & 2 & 2 & 2 \\
\hline Dropping point $\left({ }^{\circ} \mathrm{C}\right)^{\mathrm{b}}$ & 185 & $>190$ & $>180$ & $>181$ & $>140$ & 154 \\
\hline Operating temperature $\left({ }^{\circ} \mathrm{C}\right)^{\mathrm{b}}$ & -20 to +130 & -20 to +130 & -30 to +120 & -30 to +120 & -35 to +120 & -25 to +80 \\
\hline
\end{tabular}

a Grease manufacturer.

${ }^{\text {b }}$ Data supplied by the manufacturer.

Table 2

Rheological parameters of the greases, in and out of the LVE region.

\begin{tabular}{|c|c|c|c|c|c|c|c|c|}
\hline \multirow[t]{2}{*}{ Grease properties } & \multirow[t]{2}{*}{ Desig. (Units) } & \multirow[t]{2}{*}{$\gamma\left(s^{-1}\right)$} & \multicolumn{6}{|l|}{ Grease } \\
\hline & & & MG1 & MG2 & EG1 & EG2 & PG1 & PG2 \\
\hline Storage modulus & $G^{\prime}(\mathrm{Pa})$ & 0.001 & 32,976 & 38,000 & 11,201 & 10,872 & 58,969 & 8554 \\
\hline Loss modulus & $G^{\prime \prime}(\mathrm{Pa})$ & & 4643 & 5210 & 1988 & 2244 & 7376 & 969 \\
\hline Complex modulus & $G^{*}(\mathrm{~Pa})$ & & 33,301 & 35,739 & 11,376 & 11,101 & 59,429 & 8609 \\
\hline Loss factor & $\operatorname{tg}(\delta)$ & & 0.14 & 0.14 & 0.176 & 0.204 & 0.125 & 0.113 \\
\hline Storage modulus & $G^{\prime}(\mathrm{Pa})$ & 10 & 261 & 573 & 68 & 83 & 775 & 135 \\
\hline Loss modulus & $G^{\prime \prime}(\mathrm{Pa})$ & & 382 & 816 & 116 & 143 & 818 & 157 \\
\hline Complex modulus & $G^{*}(\mathrm{~Pa})$ & & 46 & 997 & 13 & 16 & 111 & 21 \\
\hline Loss factor & $\operatorname{tg}(\delta)$ & & 1.464 & 1.424 & 1.713 & 1.717 & 1.083 & 1.163 \\
\hline Consistency index & $K\left(\right.$ Pa s $\left.^{\mathrm{n}}\right)$ & $0.05-5$ & 445 & 572 & 802 & 498 & 1012 & 182 \\
\hline Flow index & $n$ & & 0.113 & 0.134 & 0.148 & 0.147 & 0.057 & 0.151 \\
\hline Apparent viscosity & $\eta(\mathrm{Pa} \mathrm{s})$ & 10 & 57.8 & 77.8 & 112.9 & 70.0 & 115.4 & 25.8 \\
\hline
\end{tabular}

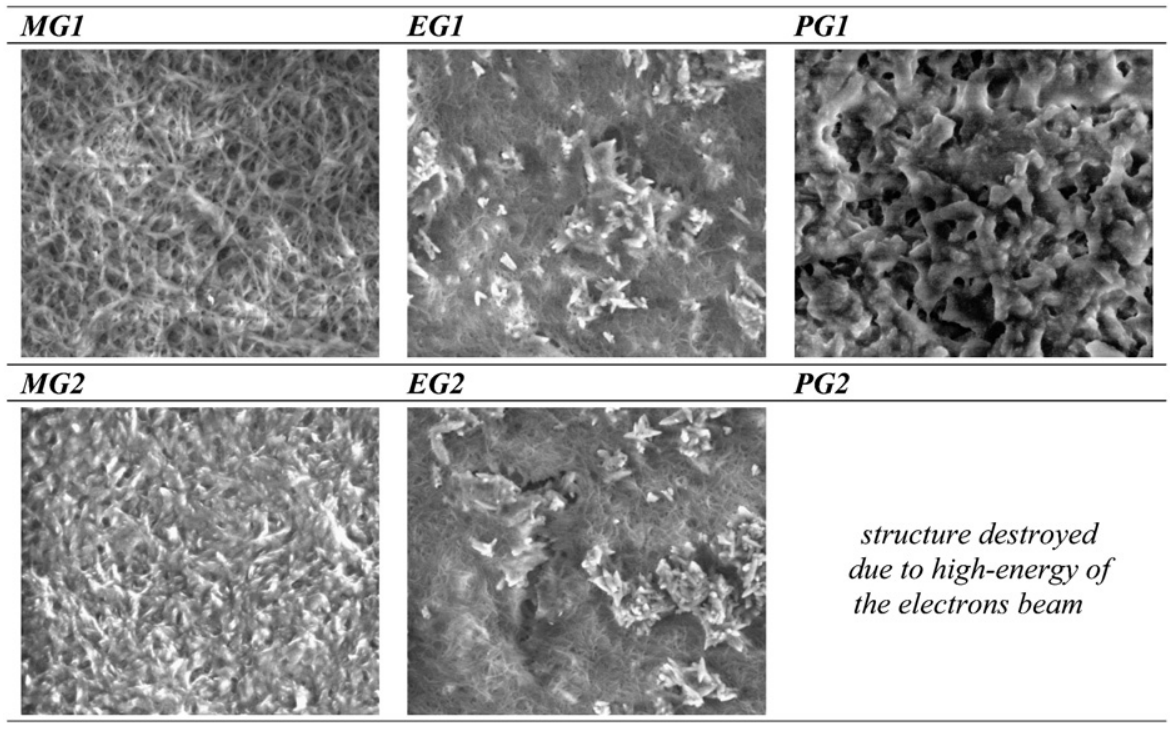

Fig. 2. SEM microphotographs of grease structures $(20,000 \times)$. 
of the series and type. This means that $R_{1}$ and $S_{1}$ values are the same for small bearings, like the 51107 tested, medium and large size bearings. As a consequence, when the bearing friction torque model is applied to the 51107 thrust ball bearing at high speeds ( $n>2000 \mathrm{rpm}$ ), the correlation between predict and experimental friction torque values would predict negative coefficients of friction in full film conditions ( $\mu_{\mathrm{EHD}}$, see Eqs. (A.8) and (A.9) in Appendix A) which are not possible.

In order to overcome this problem, thrust ball bearings were tested using fully formulated mineral, PAO and ester oils, for which the corresponding traction curves and full film coefficients of friction $\left(\mu_{\mathrm{EHD}}\right)$ were known in similar operating conditions. Knowing those $\mu_{\mathrm{EHD}}$ values it was possible to correlate the experimental and the predict friction torque values and define the adequate $R_{1}$ and $S_{1}$ constants for thrust ball bearing 51107 .

\section{Results}

\subsection{Rheological parameters}

Amplitude sweep tests allow to quantify storage and loss modulus as a function of the shear rate. The complex modulus $\left(G^{*}\right)$ is determined by the vector sum of the elastic and the viscous components of the grease, as shown in the following equation:

$G^{*}=\sqrt{G^{2}+G^{\prime \prime 2}}$

The complex modulus represents the resistance to deformation of the grease. The significant different values of complex modulus shown in Table 2, indicate that the grease has different rheological behaviours.

The complex modulus $\left(G^{*}\right)$ measured at a shear rate $(\dot{\gamma})$ of $10 \mathrm{~s}^{-1}$ is significantly lower than those measured at $0.001 \mathrm{~s}^{-1}$ (see Table 2). In the case of grease EG1, the values of $G^{*}$ are $G_{0.001}^{*}=11,375 \mathrm{~Pa}$ and $G_{10}^{*}=13 \mathrm{~Pa}$, respectively. Such trend is observed for all greases analyzed.

The flow tests were used to measure the apparent viscosity $(\eta)$ in the function of the shear rate $(\dot{\gamma})$. The Ostwald de Waele model, defined by Eq. (3), can be applied to these measurements in order to calculate the empirical values for the grease consistence $(k)$ and the flow index $(n)$ [12], shown in Table 2 .

$\eta=k \dot{\gamma}^{n-1}$

The consistence index values for all grease samples are significantly different, going from $182 \mathrm{~Pa}$ s in the case of grease PG2 to 1012 Pa s in the case of grease PG1. The flow index values are also significantly different, going from 0.057 in the case of grease PG1 to 0.151 in the case of grease PG2.

The flow index is connected with the shear thinning characteristics of the grease, e.g., low values on flow index indicate high shear thinning characteristics and better film-forming ability [13].

The complex modulus values showed opposite behaviour than the flow index, e.g., the highest values of the flow index correspond to the lowest values of the complex modulus, and consequently, it can be said that high values of the complex modulus are related to the better film-forming characteristics.

\subsection{Experimental friction torque and operating temperatures}

The measured values of the bearing friction torque are plotted against the bearing rotational speed in Fig. 3a, for all greases tested. The measurements show that the bearing torque reached

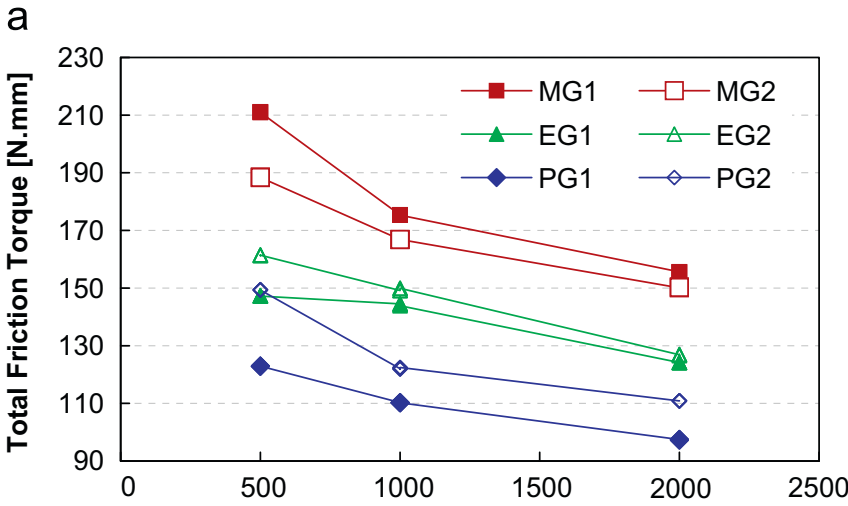

b

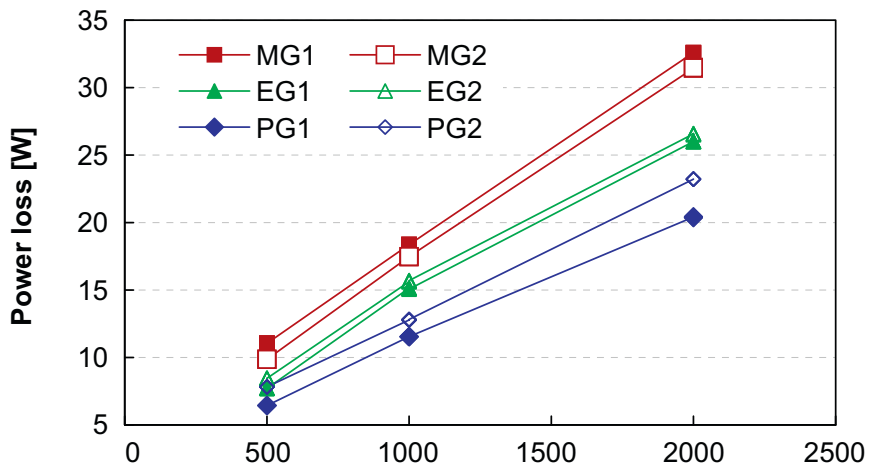

C

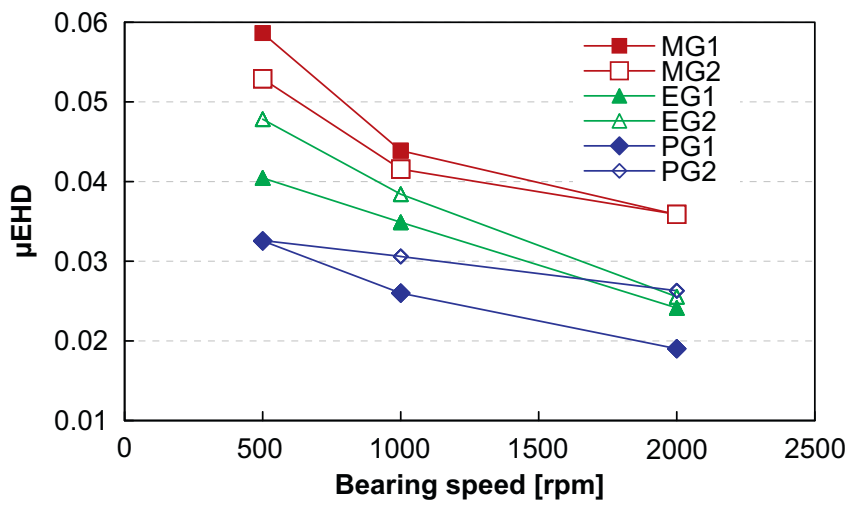

Fig. 3. (a) Friction torque measured, (b) power loss calculated and (c) full film coefficient of friction $\left(\mu_{\mathrm{EHD}}\right)$ vs. bearing speed.

the highest values with the mineral greases (MG1 and MG2) and the lowest ones with the polymeric greases (PG1 and PG2), while the torque values corresponding to the ester biodegradable greases (EG1 and EG2) were in between mineral and polymeric greases.

In general, the bearing friction torque decreases when the bearing speed increases.

The friction torque measured values were used to determine the power loss $P_{\text {loss }}(\mathrm{W})$ generated inside a thrust ball bearing, which may be calculated multiplying the bearing speed $\omega(\mathrm{rad} / \mathrm{s})$ by the friction torque $M_{\text {exp }}(\mathrm{N} \mathrm{m})$, [7], see Fig. 3b.

The highest operating temperatures measured, corresponding to thermocouple III (see Fig. 1), are plotted against the bearing speed in Fig. 4a, for all greases tested. The highest temperature values correspond to the mineral greases (MG1 and MG2), the polymeric greases (PG1 and PG2) showed the lowest ones, while the ester based greases (EG1 and EG2) presented temperatures between the other two, which is in close agreement with the 
a

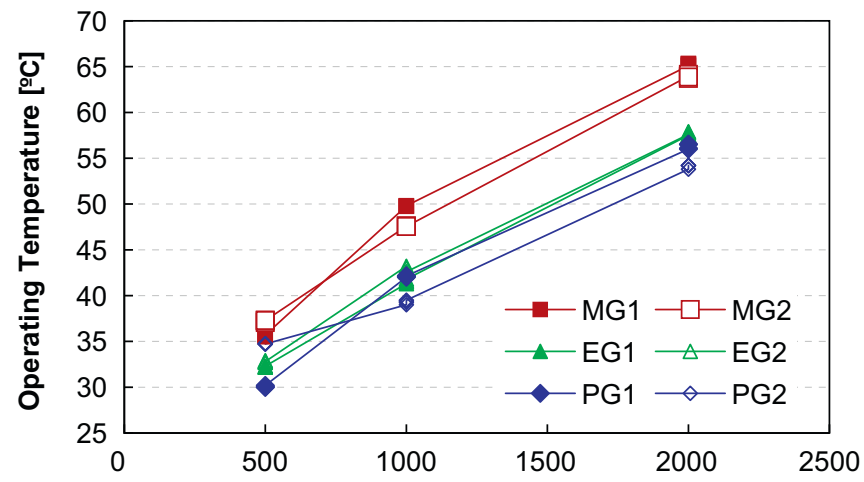

b

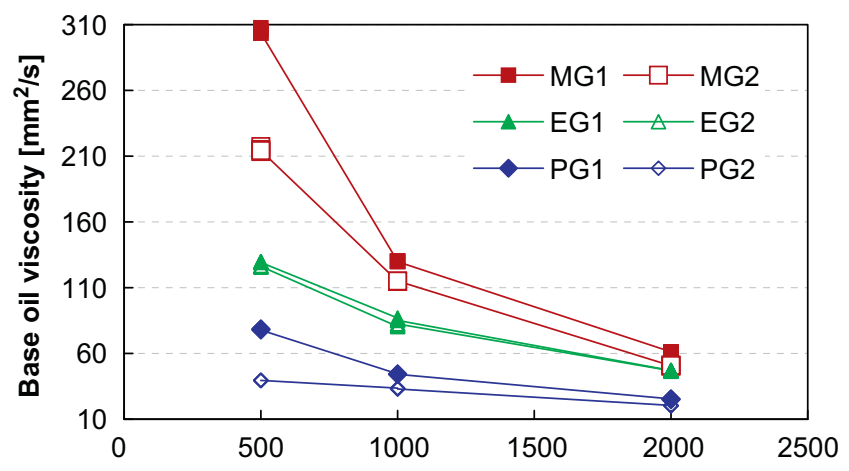

C

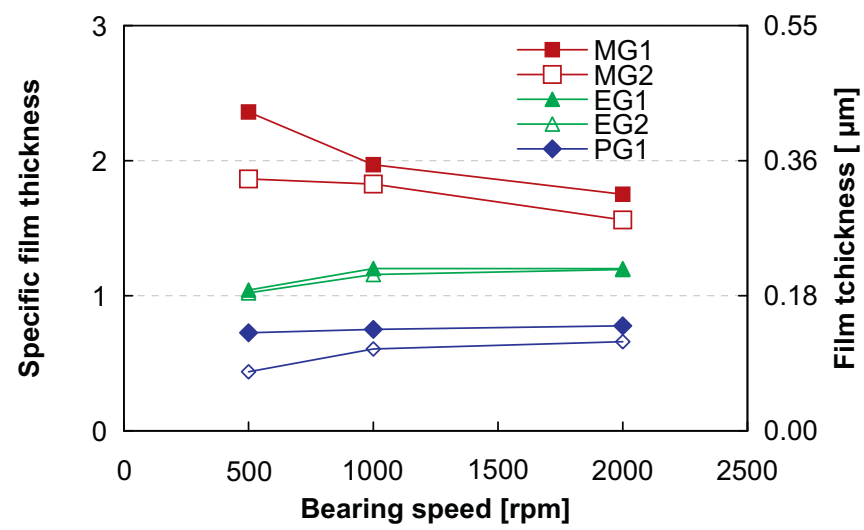

Fig. 4. (a) Operating temperature, (b) base oil viscosity and (c) specific film thickness $(\Lambda)$ and film thickness $\left(h_{0}\right)$ vs. rotational speed.

friction torque measurements: higher operating bearing torques generate higher operating bearings temperatures.

At $2000 \mathrm{rpm}$, the friction torque and the operating temperature of the grease MG1 were $155 \mathrm{~N} \mathrm{~mm}$ and $65{ }^{\circ} \mathrm{C}$, while the corresponding values for grease PG2 were $110 \mathrm{~N} \mathrm{~mm}$ and $53{ }^{\circ} \mathrm{C}$, that is, $37 \%$ and $17 \%$ lower, respectively.

\subsection{Base oil viscosity and film thickness}

Fig. 4b shows the calculated kinematic viscosities of the grease base oils at the bearing operating temperatures (ASTM D341), for each rotating speed. At $2000 \mathrm{rpm}$ the base oil of the mineral greases MG1 and MG2 has the highest kinematic viscosity (60 and $50 \mathrm{~mm}^{2} / \mathrm{s}$, respectively), followed by the base oil of the ester greases EG1 and EG2 $\left(45 \mathrm{~mm}^{2} / \mathrm{s}\right)$. The polymeric grease base oils have the lowest kinematic viscosities, 25 and $20 \mathrm{~mm}^{2} / \mathrm{s}$ for PG1 and PG2, respectively.
The base oil viscosity was used to calculate the theoretical centre film thickness in the ball-race contact of the thrust ball bearing, for each speed and grease, as shown in Fig. 4c. The centre film thickness was determined using the Hamrock and Dowson [10] equation for elliptical contacts and the base oil properties, i.e.,

$H_{0}=1.345 R_{x} U^{0.67} G^{0.530} W^{-0.067} C_{0}$

It is interesting to notice that the ester based greases (EG1 and EG2) and the polymeric greases (PG1 and PG2) followed a similar trend, with a small and almost constant film thickness. The mineral grease showed a very large film thickness at low speed (and thus low bearing operating temperature) and a significant decrease of film thickness as the bearing speed increases together with the operating temperature. The same behaviour was observed by Couronné et al. [14] in film thickness measurements, of a ball-plate contact lubricated with lithium thickened greases containing mineral and ester base oil. At $2000 \mathrm{rpm}$ the film thickness calculated for the different greases were: $0.32 \mu \mathrm{m}$ for MG1, $0.28 \mu \mathrm{m}$ for MG2, $0.22 \mu \mathrm{m}$ for EG1 and EG2, $0.14 \mu \mathrm{m}$ for PG1 and $0.12 \mu \mathrm{m}$ for PG2.

Analyzing the specific film thickness $(\Lambda)$, presented in Fig. $4 \mathrm{c}$, it can be seen that the polymeric greases (PG1 and PG2) work in the boundary regime $(\Lambda<1)$ and the other greases in mixed and full film lubrication.

\subsection{Full film coefficient of friction $\left(\mu_{E H D}\right)$ and total friction torque $\left(M_{t}\right)$}

The SKF rolling bearing friction torque model (described in Appendix A) was correlated with the experimental torque values $\left(M_{t}=M_{\exp }\right)$, taking into consideration the thrust bearings dimensions, the operating conditions (load and speed) and the rheological properties at the operating temperature, allowing the determination of the friction coefficient in full film condition, $\mu_{\mathrm{EHD}}$ (see Appendix A, Eqs. (A.12) and (A.13)).

Fig. $3 c$ shows the $\mu_{\mathrm{EHD}}$ values for each grease and operating speed. As expected the friction coefficient in full film conditions decreases when the bearing speed increases. In this correlation it was considered that the friction coefficients in boundary lubrications were $0.09,0.10$ and 0.11 for mineral, PAO and ester base oils, respectively, according to Brandão et al. [15].

Once the friction coefficient in full film lubrication is known, it is possible to plot the rolling $\left(M_{r r}\right)$, the sliding $\left(M_{s l}\right)$ and the total torques $\left(M_{t}\right)$ using the SKF model, which are plotted against bearing speed for all greases tested, as shown in Fig. 5. The rolling torque ( $M_{r r}$ - see Eqs. (A.1) and (A.2) in Appendix A) is mainly dependent on the viscosity of the base oil at the operating temperature, on the operating speed and on the replenishment of the contact $\left(\varphi_{r s}\right)$, while the sliding torque $\left(M_{s l}-\right.$ see Eq. (A.6) in Appendix A) is mainly dependent on the weighting factor $\left(\varphi_{b l}\right)$ and on the friction coefficient in full film EHD lubrication $\left(\mu_{E H D}\right)$.

Fig. 5 shows that the rolling torque $\left(M_{r r}^{\prime}=\varphi_{i s h} \varphi_{r s} M_{r r}\right)$ decreases slightly with the rotational speed for mineral greases (typical behaviour for high viscous lubricant) and increases slightly with ester and polymeric greases (typical behaviour for low viscous lubricant) [11]. Actually, the $M_{r r}^{\prime}$ increases with increasing film thickness, but begins to decrease from the moment that kinematic replenishment factor $\left(\varphi_{r s}\right)$ begins to have a significant influence.

The sliding torque $\left(M_{s l}\right)$, shows a direct relationship with the friction coefficient in full film conditions, i.e, when the specific film thickness is higher than $1(\Lambda>1)$. Near to boundary regime $(\Lambda \approx 1)$ the weighting factor $\left(\varphi_{b l}\right)$ increases considerably, the 


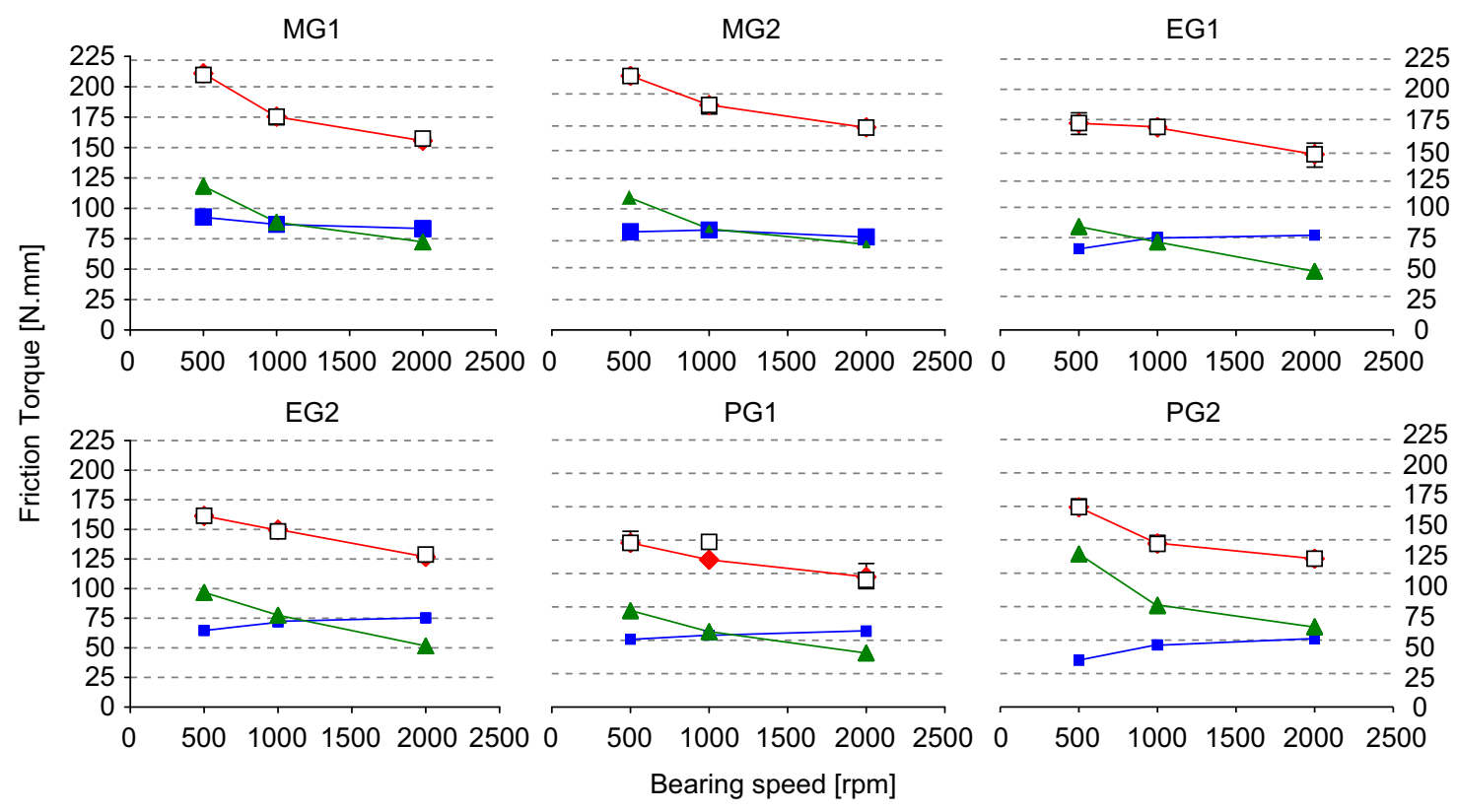

$\multimap$ Mt $\rightarrow$ Mrr $\longrightarrow$ Msl $\quad$ Mexp

Fig. 5. Experimental torque $\left(M_{\text {exp }}\right)$, rolling $\left(M_{r r}\right)$, sliding $\left(M_{s l}\right)$ and total torque $\left(M_{t}\right)$ calculated vs. rotational speed.

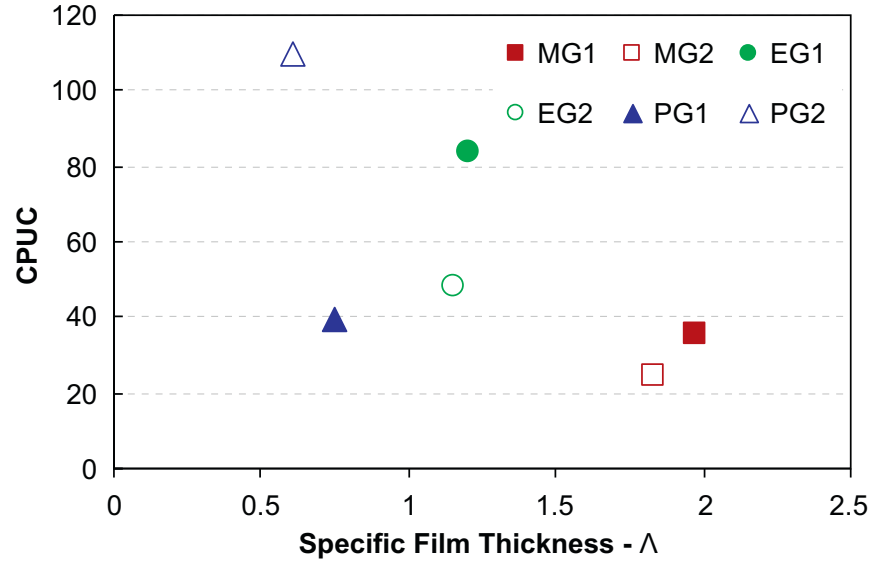

Fig. 6. Wear indexes (CPUC) vs. theoretical specific film thickness $\Lambda$ at $1000 \mathrm{rpm}$.

boundary friction coefficient becomes important and the sliding torque increases. This fact can justify the opposite behaviour of the PG1 and PG2 greases in terms of the friction torque, film thickness and base oil viscosity.

\subsection{Wear}

Ferrographic techniques were used to evaluate the wear mechanism that occurred for each grease tested in the thrust ball bearing.

Based on previous work [16], the most representative grease sample to be analyzed by ferrography was defined to be the grease located inside the bearing. So, the grease samples analyzed were obtained by carefully dismounting the thrust ball bearing from the bearing assembly, removing carefully the bearing cage with the rolling balls to be washed with solvent, using the ultrasonic agitation. For each grease sample dissolved, a known grease quantity was recorded, weighting the cage before and after being washed.

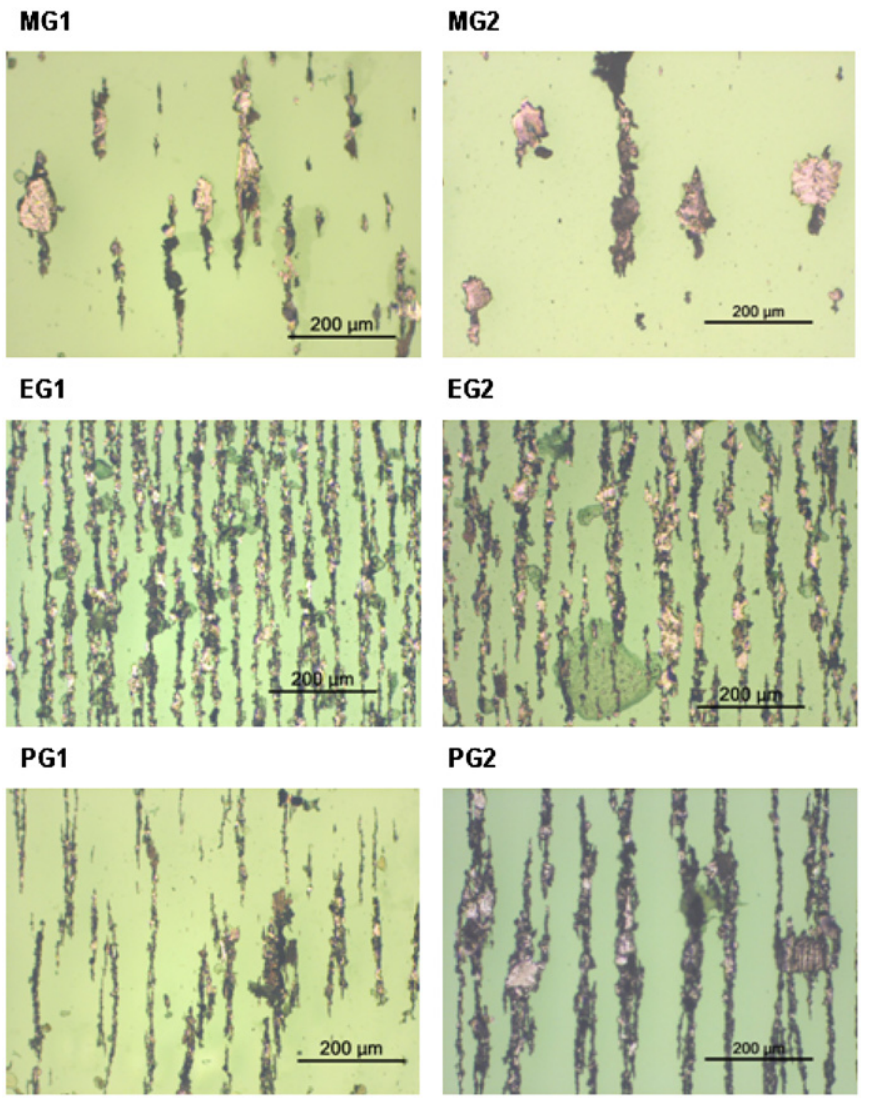

Fig. 7. Analytical Ferrography microphotographs magnified $200 \times$.

Bearing wear was evaluated using the Direct Reading Ferrograph (DRIII), where the wear particle concentration index (CPUC) was calculated for the greases tested, and through Analytical Ferrography (FMIII), using the microscopic analysis of the wear particles generated [16]. 
Fig. 6 presents the CPUC results vs. the theoretical specific film thickness calculated for all greases. As shown, the wear particle concentration index decreases as the specific film thickness increases. The ester based greases (EG1, EG2 and PG2) generated the higher wear indexes, while the mineral greases (MG1 and MG2), having high specific film thickness, generated lower wear particles concentrations. In spite of the low theoretical specific film thickness of grease PG1, the wear particle concentration index obtained was relatively low.

Pictures taken from ferrographs obtained by Analytical Ferrography, presented in Fig. 7, indicate that:

- The mineral-based greases (MG1 and MG2) generated few wear particles. Most of these particles are laminar, large in size and with irregular forms, typical from severe wear rolling bearing. The ferrograms clearly show the relative absence of normal rubbing wear (small particles). The high ratio of large particles $(\geq 20 \mu \mathrm{m})$ to small particles $(<2 \mu \mathrm{m})$ indicates a more severe type of wear [17]. In fact the large particles observed were similar to those generated during rolling bearing fatigue.

- Ester based greases (EG1 and EG2) generated a large amount of wear particles with small and medium sizes, but also few wear particles with large size. The presence of particles resulting for rubbing wear is considerable. However, there are some large wear particles resulting from severe wear.

- Polymeric grease PG1 generated a minor amount of wear particles with small and medium sizes. Polymeric grease PG2 produced the most severe wear with high concentration of small and large wear particles and some of these large particles show evidences of severe sliding wear with surface striations and thermal oxidation. The presence of severe rolling wear particles is also noticed, with smooth surface but showing some plastic deformation.

\section{Discussion and conclusions}

Despite of the highly complex behaviour of lubricant greases, the results obtained are in line with other studies of leading researches in the same field [14]. A qualitative analysis of the results suggests that the base oil properties and the interaction between base-oil and thickener are the predominant factors in the tribological behaviour of a grease lubricated thrust ball bearing.

In Table 3 a summary of the most relevant parameters is provided at an operating speed of $1000 \mathrm{rpm}$. The first remark is about the influence of the base oil viscosity $(v)$, since greases formulated with higher viscosity base-oils generate higher operating temperatures $(T)$ and higher rolling friction torque $\left(M_{r r}\right)$, as shown in Table 3, comparing the $v$ and $M_{r r}$ values for all greases.
However, grease formulation and in particular the interaction between thickener and base oil, can influence contact replenishment, contact starvation and thus the rolling friction torque $\left(M_{r r}\right)$. This means that the two greases with identical base oil viscosity tend to generate the same rolling friction torque, but the one with lower contact replenishment (higher starvation) will show the lowest $M_{r r}$. Thus each grease will have its own kinematic replenishment factor $\left(\varphi_{r s}\right)$, which depends on grease rheology.

Couronné et al. [14] reported that ester based greases thickened with lithium (like EG1) generate significant lubricant starvation and this type of grease has a high flow index $(n)$. The same is observed with grease PG2.

For the moment, the bearing torque model does not take into account the influence of any rheological parameter related to the interaction between thickener and base oil. Such characterization needs specific measurements of film thickness in grease lubricated contacts, which are the next stage of this work.

Table 3 also presents the lubricant parameter $(L P)$ values at the operating temperature. The lubricant parameter is very interesting because it not only includes the influence of the base oil viscosity $(\eta)$ but also the influence of the base oil piezoviscosity $(\alpha)$, which is strongly dependent on the nature of the base oil (mineral, ester and PAO).

Brandão et al. [15], have recently shown that fully formulated oils with lower lubricant parameter also have lower coefficient of friction in full film conditions $\left(\mu_{\mathrm{EHD}}\right)$. This is also observed when $L P$ and $\mu_{\mathrm{EHD}}$ values for greases MG1, MG2, EG1 and PG2 are compared, as shown in Table 3. So, base oil with higher $L P$ values will have higher friction coefficients in full film conditions $\left(\mu_{\mathrm{EHD}}\right)$ and, consequently, will generate higher sliding torques $\left(M_{s l}\right)$. However, the sliding torque also depends on the interaction between asperities inside the contact (mixed film lubrication) and on grease additives, which can affect the lubricant shearing mechanisms through parameters $\varphi_{b l}$ (mixed film condition) and $\mu_{b l}$ (additives package and base oil nature), respectively (see Appendix A, Eqs. (A.9) and (A.10)).

The lubricant parameter is also directly related to the specific film thickness $(\Lambda)$ in an EHD contact; high $L P$ values generate high specific film thickness, as shown in Table 3.

If the $L P$ value is small, the specific lubricant film thickness becomes very small $(\Lambda>1)$, mixed/boundary lubrication occurs and the sliding torque can increase significantly. This was clearly observed in the case of PG2 $(\Lambda=0.67)$ that has higher sliding torque $\left(M_{s l}\right)$ than greases EG1 and PG1 despite of the lowest $L P$ and $\mu_{\mathrm{EHD}}$ values.

So, if the sliding friction torque is very sensitive to film thickness, mainly in mixed and boundary lubrication, it is also strongly dependent on lubricant starvation and on the interaction between base oil and thickener. This also means that each grease will have its own mixed film factor $\left(\varphi_{b l}\right)$, which depends on grease rheology.

Table 3

Grease properties and bearing friction torque at an operating speed of $1000 \mathrm{rpm}$.

\begin{tabular}{|c|c|c|c|c|c|c|}
\hline \multirow{2}{*}{$\begin{array}{l}\text { Operating parameters at } 1000 \mathrm{rpm} \\
\text { Thickener }\end{array}$} & \multirow{2}{*}{ Desig. and units } & \multicolumn{5}{|c|}{ Lubricating greases } \\
\hline & & $\mathrm{Li}$ & $\mathrm{Li}$ & $\mathrm{Li}$ & Polypropylene & Polypropylene \\
\hline Case oil & 1 & Mineral & Mineral & Ester & PAO & Ester+vegetal \\
\hline Reference & 1 & MG1 & MG2 & EG1 & PG1 & PG2 \\
\hline Temperature & $T\left({ }^{\circ} \mathrm{C}\right)$ & 49.8 & 47.6 & 41.6 & 42.1 & 39.3 \\
\hline Base oil viscosity & $v\left(\mathrm{~mm}^{2} / \mathrm{s}\right)$ & 129.8 & 151.1 & 85.1 & 44.1 & 33.0 \\
\hline Lubricant parameter & $L P \times 10^{-9}$ & 2.23 & 1.98 & 0.94 & 0.46 & 0.32 \\
\hline Rolling friction torque & $M_{r r}(\mathrm{~N} \mathrm{~mm})$ & 86.8 & 83.0 & 73.4 & 53.7 & 46.1 \\
\hline Flow index & $n$ & 0.11 & 0.12 & 0.15 & 0.15 & 0.06 \\
\hline Sliding friction torque & $M_{s l}(\mathrm{~N} \mathrm{~mm})$ & 88.5 & 83.8 & 70.4 & 56.4 & 76.3 \\
\hline$\mu_{\mathrm{EHD}}$ & 1 & 0.044 & 0.042 & 0.035 & 0.026 & 0.030 \\
\hline Specific film thickness & $\Lambda$ & 1.97 & 1.83 & 1.20 & 0.75 & 0.61 \\
\hline CPUC & 1 & 35 & 25 & 84 & 40 & 110 \\
\hline
\end{tabular}


Here, again, the relation between grease rheology (flow index) and contact starvation will be fundamental to integrate the influence of thickener/base oil interaction on the bearing friction model.

The results obtained for the rolling and sliding bearing friction torques, are mainly dependent on the properties of the grease base oil: viscosity, lubricant parameter and nature (mineral, ester and PAO). However, the film thickness inside the contact depends not only on the lubricant parameter but also on lubricant starvation, which depends on the interaction between grease thickener and base oil and on grease rheology (flow index, complex modulus, etc.).

If the interaction between thickener and base oil generates significant lubricant starvation, the film thickness is small, the rolling friction torque decreases and the sliding friction torque increases. Greases EG1 and PG2 have high values of flow index and seem to be affected by this phenomenon, and probably operate under considerably lower film thickness than the theoretical values. This is suggested by the high CPUC (index for concentration of wear particles) values measured for these two greases (see Table 3).

\section{Acknowledgements}

The authors would like to thank the "Fundação para a Ciência e Tecnologia" (FCT) of the Portuguese Administration for support given to this study through the research project "Low friction, biodegradable and low-toxicity greases for rolling bearings" (Ref. PTDC/EME-PME/72641/2006).

The authors would like to thank Dr. Harold Bock from ROWE Mineralölwerk Gmbh, in Bubenheim, Germany, for supplying the ester based greases EG1 and EG2, and Dr. Michael Kruse from AXEL Christiernsson AB, Sweden, for supplying the polymer thickened greases PG1 and PG2.

\section{Appendix A}

The new SKF bearing friction torque model developed by SKF, separates friction torque in the true physical friction sources, which includes a term for the rolling torque $-M_{r r}$, a term for sliding torque $-M_{s l}$, a term for the mechanical drag torque $-M_{\text {drag }}$ and a term for a frictional torque of seals $\left(M_{\text {seal }}\right)$, as shown in Eq. (1)

$M_{\text {total }}=\varphi_{\text {ish }} \varphi_{r s} \underbrace{\left(G_{r r}(v n)^{0.6}\right)}_{M_{r r}}+\underbrace{\left(G_{s l}\left(\mu_{\text {sl }}\right)\right)}_{M_{s l}}+\underbrace{\left(V_{M} K_{\text {ball }} d_{m}{ }^{5} n^{2}\right)}_{M_{\text {drag }}}+\underbrace{\left(K_{S 1} d_{s}^{\beta}+K_{S 2}\right)}_{M_{\text {seal }}}$

Rolling frictional moment $-M_{r r}$

There are several sources of rolling friction losses in the rolling contacts. Energy is spent to introduce the lubricant into the contact and to reject the excess (elastohydrodynamic lubrication process). Elastic hysteresis losses in the steel (energy dissipation in the deformation process) and even adhesion forces between surfaces are mechanisms that can generate rolling friction.

The rolling frictional moment is calculated from the equation

$M_{r r}=G_{r r}(v n)^{0.6}$

where $M_{r r}$ is the rolling frictional moment ( $\left.\mathrm{N} \mathrm{mm}\right), G_{r r}$ represents the influence of the bearing load on the rolling resistance and depends on the bearing type, the bearing mean diameter $(\mathrm{mm})$ and the axial load $(\mathrm{N}), n$ the rotational speed $(\mathrm{m} / \mathrm{s})$ and $v$ the kinematic viscosity of the lubricant at the operating temperature (for grease lubrication the vase oil viscosity must be used) $\left(\mathrm{mm}^{2} / \mathrm{s}\right)$.
For thrust ball bearings, the rolling friction variable $\left(G_{r r}\right)$ is given by

$G_{r r}=R_{1} d_{m}{ }^{1.83} F_{a}{ }^{0.54}$

where $R_{1}$ is the geometry constant for rolling frictional moments and is dependent on the type of bearing $1.03 \times 10^{-6}$ for thrust ball bearings, $d_{m}$ the bearing mean diameter $(\mathrm{mm})$ and $F_{a}$ the axial $\operatorname{load}(\mathrm{N})$.

However the rolling friction resistance is affected by other factors-in inlet shear heating and kinematic replenishment/ starvation.

Inlet shear heating $\varphi_{\text {ish }}$ : occurs because not all the lubricants present at the inlet of the contact manage to get inside; some of it will recirculate in the inlet because of the reverse flow. This recirculation produces heat, since the viscosity of the lubricant is highly reduced by the temperature; lower viscosity at the inlet of the contact means lower film thickness and, therefore, lower rolling resistance. This effect is taken into account in the SKF friction model by means of the multiplication factor $\varphi_{i s h}$, which is calculated by

$\varphi_{\text {ish }}=\frac{1}{1+1.84 \times 10^{-9}\left[\left(n d_{m}\right)^{1.28} v^{0.64}\right]}$

Kinematic replenishment/starvation $\varphi_{r s}$ : occurs when high speeds or high lubricant viscosities hamper the replenishment of lubricant in the raceway after a rolling element has passed, since the lubricant will not have sufficient time to flow back from the sides to the centre of the raceway. This is a kinematic starvation, which will produce a reduction of the lubricant availability in the inlet of the contact and reduce the film thickness and the rolling resistance. The replenishment/starvation effect is considered in the SKF friction model by means of the multiplication factor $\varphi_{r s}$. This factor is a function of the lubricant supply mechanism as well and is calculated by

$\varphi_{r s}=\frac{1}{e^{K r s v n(d+D) \sqrt{K_{z} / 2(D-d)}}}$

where $K_{r s}$ is the replenishment starvation constant, $6 \times 10^{-8}$ for greases and $K_{z}$ the bearing type related geometry constant, 3.8.

Sliding frictional moment $-M_{s l}$

Sliding friction in rolling contacts is always present. There are two important sources of sliding in a rolling contact, the macrosliding and the micro-sliding.

The sliding frictional moment is calculated from the equation

$M_{s l}=G_{s l} \mu_{s l}$

where $M_{s l}$ is the sliding frictional moment ( $\left.\mathrm{N} \mathrm{mm}\right), G_{s l}$ represents the influence of the bearing load in the sliding resistance and depends on the bearing type, the bearing mean diameter ( $\mathrm{mm}$ ) and the axial load ( $\mathrm{N}$ ) and $\mu_{s l}$ the sliding friction coefficient.

For thrust ball bearings, the sliding friction variable (Gsl) is given by

$G_{s l}=S_{1} d_{m}{ }^{0.05} F_{a}{ }^{4 / 3}$

where $S_{1}$ is a geometry constant for sliding frictional moments and is dependent on the type of bearing. $1.6 \times 10^{-2}$ for thrust ball bearings, $d_{m}$ the bearing mean diameter $(\mathrm{mm})$ and $F_{a}$ the axial load $(\mathrm{N})$.

The sliding friction coefficient is affected by the macro-sliding caused by contact conformity due to macro-geometry features, e.g., the contact between balls and curved raceways in ball bearings (osculation) and spinning, which is sliding with angular velocity, and micro-sliding caused by the geometrical distortion from elastic deformation. The slip profile in the contact area will 
produce friction losses by means of lubricant shearing or/and asperity contact, depending on the film thickness/roughness ratio.

Lubricant shearing: the friction coefficient due to lubricant shearing in one contact is

$\mu_{\mathrm{EHD}}=\frac{1}{Q} \int_{A} \tau d A$

where $Q$ is the normal load in the contact, $\tau$ the shear stress in the lubricant, $A$ the contact area and $\mu_{\mathrm{EHD}}$ the friction coefficient in full film conditions. The shear stress in the contact will depend on the slip profile (sliding speed) and the lubricant rheology.

Asperity contact: when the film thickness is not sufficient to completely separate the surfaces and with the presence of slip, some asperity interaction could take place. This will increase the friction losses from sliding, since the friction coefficient of the asperities is larger than from shearing the oil. The following equation gives the total friction coefficient coming from shearing the oil and from asperity contacts:

$\mu_{s l}=\varphi_{b l} \mu_{b l}+\left(1-\varphi_{b l}\right) \mu_{\mathrm{EHL}}$

where $\mu_{b l}$ is the friction coefficient between the interacting asperities, it is influenced by the lubricant additive package. The function $\varphi_{b l}$ is a weighting factor for the influence of asperity and lubricant shearing mechanisms and is determined by the following equation:

$\varphi_{b l}=\frac{1}{e^{2.6 \times 10^{-8}(n v)^{1.4} d_{m}}}$

Modelling and experimentation have been used by SKF to obtain this equation.

Since the thrust ball bearing (Ref. SKF 51107) has no seals and the drag losses produced by lubricating greases tend to zero, only the rolling and sliding torque were considered. So, expression (A.1) can be rewritten as

$M_{\text {total }}=\varphi_{i s h} \varphi_{r s} M_{r r}+M_{s l}$

Through correlation with the experimental friction torque measured $\left(M_{\text {total }}=M_{\exp }\right)$ is possible to determine the sliding friction torque $\left(M_{s l}\right)$,

$M_{s l}=M_{\exp }-\varphi_{i s h} \varphi_{r s} M_{r r}$

and thus the coefficient of friction in full film conditions $\left(\mu_{\mathrm{EHD}}\right)$ can be obtained, that is

$\mu_{\mathrm{EHL}}=\frac{\frac{M_{s l}}{G_{s l}}-\varphi_{b l} \mu_{b l}}{\left(1-\varphi_{b l}\right)}$

taking into account Eqs. (A.6) and (A.9).

\section{Appendix B}

Notation

\begin{tabular}{|c|c|}
\hline $\begin{array}{l}A \\
C_{0} \\
d_{m}\end{array}$ & $\begin{array}{l}\text { Contact area }\left(\mathrm{mm}^{2}\right) \\
\text { ellipticity influence parameter }(-) \\
\text { bearing mean diameter }(\mathrm{mm})\end{array}$ \\
\hline$d_{s}^{\beta}$ & $\begin{array}{l}\text { seal counterface diameter; exponent depending } \\
\text { bearing and seal type (-) }\end{array}$ \\
\hline$F_{a}$ & axial load $(\mathrm{N})$ \\
\hline G & material parameter (-); shear modulus (Pa) \\
\hline$G_{r r}, G_{s l}$ & $\begin{array}{l}\text { factor that depends on the bearing type, bearing me } \\
\text { diameter and applied load }(-)\end{array}$ \\
\hline$H_{0}$ & centre film thickness $(\mu \mathrm{m})$ \\
\hline$K_{\text {ball }}$ & ball bearing relating constant $(-)$ \\
\hline
\end{tabular}

$K_{r s} \quad$ replenishment/starvation constant $-6 \times 10^{-8}(-)$

$K_{z} \quad$ bearing type related geometry constant (-)

KS1 constant depending on the bearing type (-)

KS2

$M_{\text {exp }} \quad$ friction torque measured ( $\mathrm{N} \mathrm{mm}$ )

$M_{r r} \quad$ rolling friction torque $(\mathrm{N} \mathrm{mm})$

$M_{s l} \quad$ sliding friction torque $(\mathrm{N} \mathrm{mm})$

$M_{\text {drag }} \quad$ friction torque of drag losses ( $\mathrm{N} \mathrm{mm}$ )

$M_{\text {seal }} \quad$ friction torque of seals ( $\mathrm{N} \mathrm{mm}$ )

$M_{\text {total }}$ total friction torque in a rolling bearing $(\mathrm{N} \mathrm{mm})$

$n$

$P_{\text {loss }}$

$R_{x} \quad$ equivalent radius $(\mathrm{mm})$

$R_{1} \quad$ geometry constant for rolling frictional moment (-)

$S_{1} \quad$ geometry constant for sliding frictional moment (-)

Q normal load in the contact $(\mathrm{N})$

$U \quad$ speed parameter (-)

$V_{M} \quad$ factor dependent on base oil level and bearing diameter

$W \quad$ load parameter $(-)$

$\varphi_{b l} \quad$ Weighting factor for the sliding frictional moment (-)

$\varphi_{\text {ish }} \quad$ inlet shear heating reduction factor (-)

$\varphi_{r s} \quad$ kinematic replenishment/starvation reduction factor (-)

$\eta \quad$ apparent viscosity (Pa s)

$\mu_{\mathrm{EHL}} \quad$ Friction coefficient in full film conditions (-)

$\mu_{\mathrm{sl}} \quad$ Sliding friction coefficient (-)

$v \quad$ kinematic viscosity at the operating temperature $\left(\mathrm{mm}^{2} / \mathrm{s}\right)$

$\tau \quad$ shear stress in the lubricant $\left(\mathrm{N} / \mathrm{mm}^{2}\right)$

$\Lambda \quad$ specific film thickness $(\mu \mathrm{m})$

$\omega \quad$ bearing speed $(\mathrm{rad} / \mathrm{s})$

\section{References}

[1] Holmberg K. Friction science saves energy. VTT Impulse 2009;2:18-25

[2] Cann PM. Grease lubrication of rolling element bearings-role of the grease thickener. Lubrication Science 2007;18(3):183-96.

[3] Lugt MP. Review on grease lubrication in rolling bearings. Tribology Transactions 2009;52(4):470-80.

[4] Cann PM, Hurley S. Friction properties of grease in elastohydrodynamic lubrication. NLGI Spokesman 2002;66:6-15.

[5] Rong-Hua J. Effects of the composition and fibrous texture of lithium soap grease on wear and friction. Tribology International 1985;18:121-124.

[6] Delgado MA, Franco JM, Kuhn E. Effect of rheological behaviour of lithium grease on the friction process. Industrial Lubrication and Tribology 2008;60(1):37-45.

[7] SKF General Catalogue 6000 EN, November 2005.

[8] Cousseau T., Graça B., Campos A., Seabra J. Experimental measuring procedure for the friction torque in rolling bearings. Lubrication Science, press, doi:10.1002/ls.115.

[9] Gold P, Schmidt A, Dicke H, Loos J, Assmann C. Viscosity-pressuretemperature behaviour of mineral and synthetic oils. Journal of Synthetic Lubrication 2001;18(1):51-79.

[10] Hamrock BJ, Dowson D. Ball bearing lubrication, the elastohydrodynamics of elliptical contacts. John Wiley \& Sons; 1981.

[11] Espejel G. Using a friction model as engineering tool. Evolution SKF 2006;06(2):27-30.

[12] Cousseau T., Graça B., Campos A., Seabra J. Influence of grease lubrication on thrust bearing power loss. In: Proceedings of the IMechE vol. 224 Part J: Journal of Engineering Tribology, in press, doi:10.1243/13506501JET724.

[13] Bair S. High pressure rheology for quantitative elastohydrodynamics. Tribology and Interface Engineering Series 2007;54:177-178.

[14] Couronné I, Mazuyer D, Vergne P, Truong-Dinh N, Girodin D. Effects of grease composition and structure on film thickness in rolling contact. Tribology Transactions 2003;46(1):31-6.

[15] Brandão AJ., Meheux M., Ville F., Castro J., Seabra J. Experimental traction and Stribeck curves of mineral, PAO and ester based fully formulated gear oils. In: Proceedings of the third international conference on integrity, reliability and failure, Porto, Portugal, 20-24 July 2009.

[16] Graça B., Campos A., Seabra J. Analysis of lubricating grease by ferrography. In: Proceedings of the fifth international conference on mechanics and materials in design, Porto, Portugal, 24-26 July 2006.

[17] Anderson DP., Wear particle atlas (Revised). In: SOHIO predictive maintenance service, NJ, 1982, p. 52-56. 